\title{
Spin Wave Measurements of Exchange Constant in Ni-Fe Alloy Films
}

\author{
CHARLES H. WILTS AND STEFAN K. C. LAI
}

\begin{abstract}
The ferromagnetic exchange constant has been measured using spin wave resonance in a number of iron-nickel alloys covering the composition range $60 \%$ to $90 \%$ nickel. The exchange constant varies smoothly from a value of $1.3\left(10^{-6}\right)$ $\mathrm{erg} \cdot \mathrm{cm}^{-1}$ at $60 \% \mathrm{Ni}$ to an extrapolated value of $0.77\left(10^{-6}\right)$ at $100 \% \mathrm{Ni}$. The data are in significant disagreement with the values published by Rusov.
\end{abstract}

\section{INTRODUCTION}

Several experimental methods have been proposed for measurement of the ferromagnetic exchange constant. For metal ferromagnets, the use of spin wave resonance with thin films appears to offer the most convenient method for accurate measurements. $[1,2]$ A number of determinations have been made for pure nickel and for the iron-nickel alloy near $80 \% \mathrm{Ni}$ with a surprising spread in the reported value of the exchange constant. [3] Published data for other Ni-Fe alloys is very sparse, the most comprehensive study being that of Rusov. [4]

In a recent report, Bajorek and Wilts [5] have conjectured that a primary cause for the lack of consistency lies in differing identification of the wavenumber for each mode because of differing assumptions regarding the surface boundary condition. They showed that consistent results could be obtained for $81 \% \mathrm{Ni}$ alloys using spin wave resonance if the following criteria were applied. 1) At a fixed frequency the plot of resonant field versus mode number squared must be accurately fitted by a straight line, except for the first 2 or 3 modes. This must hold for a number of samples covering a wide range of film thickness (e.g., $1500 \AA$ to $10000 \AA$ ). 2) The slopes of these lines must correspond to a unique value of $A$ independent of film thickness. Their conclusion was that one should use even number mode assignments for the principal resonances, obtaining a value $A=1.03 \times 10^{-6} \mathrm{erg} / \mathrm{cm}$. Rusov, using similar criteria, concluded that one should use odd number mode assignments and reported a value of $A=0.96 \times 10^{-6}$ for the same composition. These values are in significant but not serious disagreement, but the difference in mode assignment and the large disagreement in other published values suggest that another independent survey should be undertaken.

Manuscript received March 3, 1972; revised June 21, 1972. Paper 3.5, presented at the 1972 INTERMAG Conference, Kyoto, Japan, April 10-13.

The authors are with the California Institute of Technology, Pasadena, Calif. 91109.

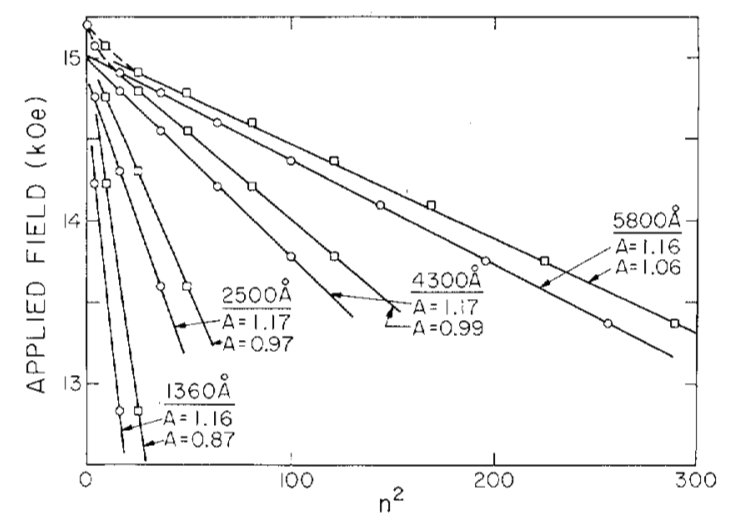

Fig. 1. Resonant field versus mode number squared for $71 \% \mathrm{Ni}-29 \%$ Fe films.

\section{EXPERIMENTAL METHODS AND RESULTS}

Sample preparation and measurement techniques are essentially the same as that given in Ref. 5. Films were evaporated by induction heating of 20 gram samples in a vacuum of $10^{-6}$ Torr or better onto glass substrates held at $200^{\circ} \mathrm{C}$ and at a rate of about $20 \AA / \mathrm{s}$. In each evaporation, 16 samples were prepared using a shutter which allowed preparation of 4 samples at each of 4 different thicknesses. The thickness of one sample from each group was measured with a Tolansky single beam multiple-reflection interferometer with estimated accuracy $\pm 1 \%$, except for films near $1000 \AA$, where the accuracy is estimated to be $\pm 2 \%$. Saturation magnetization $M$ was measured using a low frequency hysteresis loop tracer and film composition was determined by X-ray fluorescence. Resonance measurements were made with a static magnetic field perpendicular to the film plane and with the sample in a stripline driven by oscillators in the 2 to $8 \mathrm{GHz}$ range. The exchange constant was obtained using the relation

$$
A=\frac{M t^{2}}{2 \pi^{2}} \frac{\Delta H}{n^{2}}
$$

where $t$ is film thickness and $\left(\Delta H / n^{2}\right)$ is the slope of the straight line which gives best fit to the plot of resonant field versus mode number squared. The gyromagnetic ratio $\gamma$ and the corresponding $g$ value were obtained from the slope of a resonant frequency of a given mode versus frequency.

A typical plot of resonance field versus mode number squared is shown in Fig. 1 for both odd and even mode number assignment. The corresponding values of exchange are given in the figure. It can be seen that if the first 1 or 2 modes are ignored, both mode assignments give a good straight line fit. However, for films thicker than $4000 \AA$, where a large number of modes are observed, the fit is distinctly better for 
TABLE I

\begin{tabular}{|c|c|c|c|c|c|}
\hline $\begin{array}{l}\text { Composition } \\
\qquad \% \mathrm{Ni}\end{array}$ & $\begin{array}{c}4 \pi \mathrm{M} \\
\mathrm{K} \text { Gauss }\end{array}$ & $\begin{array}{c}\text { Thickness } \\
\stackrel{\circ}{A}\end{array}$ & $g$ & \multicolumn{2}{|c|}{$\begin{array}{c}\text { A } \\
10^{-6} \mathrm{erg} \cdot \mathrm{cm}^{-1}\end{array}$} \\
\hline & & & & Even & odd \\
\hline 100 & & $\begin{array}{l}1500 \\
3100 \\
5200 \\
\end{array}$ & $\begin{array}{l}2.13 \\
2.15 \\
2.14 \\
\end{array}$ & & \\
\hline 96.0 & & $\begin{array}{l}2000 \\
3000 \\
4400\end{array}$ & $\begin{array}{l}2.12 \\
2.14 \\
2.14\end{array}$ & & \\
\hline 90.6 & 8.2 & $\begin{array}{l}2300 \\
4500 \\
6600 \\
\end{array}$ & $\begin{array}{l}2.10 \\
2.09 \\
2.10 \\
\end{array}$ & $\begin{array}{l}.92 \\
.90 \\
.88 \\
\end{array}$ & $\begin{array}{l}.69 \\
.77 \\
.78 \\
\end{array}$ \\
\hline 82.0 & 10.0 & $\begin{array}{l}2000 \\
3900 \\
6000 \\
\end{array}$ & $\begin{array}{l}2.10 \\
2.11 \\
2.09 \\
\end{array}$ & $\begin{array}{r}1.01 \\
.97 \\
1.03 \\
\end{array}$ & $\begin{array}{l}.76 \\
.83 \\
.93 \\
\end{array}$ \\
\hline 81.5 & 10.1 & $\begin{array}{l}1040 \\
1800 \\
2300 \\
\end{array}$ & & $\begin{array}{l}1.01 \\
1.03 \\
1.04 \\
\end{array}$ & $\begin{array}{l}.60 \\
.73 \\
.78 \\
\end{array}$ \\
\hline $75.9(8)$ & & $\begin{array}{l}2800 \\
4000 \\
\end{array}$ & & $\begin{array}{l}1.08 \\
1.05 \\
\end{array}$ & \\
\hline 71.0 & 13.2 & $\begin{array}{l}1360 \\
2500 \\
4300 \\
5800\end{array}$ & $\begin{array}{l}2.09 \\
2.08\end{array}$ & $\begin{array}{l}1.15 \\
1.17 \\
1.16 \\
1.16\end{array}$ & $\begin{array}{r}.87 \\
.97 \\
.99 \\
1.06 \\
\end{array}$ \\
\hline 69.2 & 12.5 & $\begin{array}{l}2500 \\
3600 \\
5300\end{array}$ & 2.08 & $\begin{array}{l}1.15 \\
1.11 \\
1.12\end{array}$ & $\begin{array}{r}.96 \\
+\quad .96 \\
1.00 \\
\end{array}$ \\
\hline 66.8 & 13.1 & $\begin{array}{l}3100 \\
5500 \\
\end{array}$ & $\begin{array}{l}2.07 \\
2.08 \\
\end{array}$ & $\begin{array}{l}1.24 \\
1.22 \\
\end{array}$ & $\begin{array}{l}1.05 \\
1.10 \\
\end{array}$ \\
\hline 65.7 & 13.7 & $\begin{array}{l}2300 \\
4100 \\
6000 \\
7100 \\
\end{array}$ & $\begin{array}{l}2.07 \\
2.07\end{array}$ & $\begin{array}{l}1.24 \\
1.27 \\
1.27 \\
1.25 \\
\end{array}$ & $\begin{array}{l}1.03 \\
1.11 \\
1.15 \\
1.13 \\
\end{array}$ \\
\hline 62.7 & 14.0 & $\begin{array}{l}1900 \\
3800 \\
6900 \\
\end{array}$ & $\begin{array}{l}2.08 \\
2.07 \\
\end{array}$ & $\begin{array}{l}1.34 \\
1.29 \\
1.26 \\
\end{array}$ & $\begin{array}{l}1.00 \\
1.08 \\
1.15 \\
\end{array}$ \\
\hline 62.6 & 14.2 & $\begin{array}{l}3600 \\
4900 \\
6900 \\
\end{array}$ & $\begin{array}{l}2.07 \\
2.06\end{array}$ & $\begin{array}{l}1.27 \\
1.25 \\
1.27\end{array}$ & $\begin{array}{l}1.05 \\
1.08 \\
1.12 \\
\end{array}$ \\
\hline 60.1 & 14.9 & $\begin{array}{l}2400 \\
5000 \\
7300 \\
\end{array}$ & 2.08 & $\begin{array}{l}1.30 \\
1.35 \\
1.30 \\
\end{array}$ & $\begin{array}{l}1.08 \\
1.20 \\
1.21 \\
\end{array}$ \\
\hline
\end{tabular}

the even number assignment. Furthermore, for even mode numbers, the values of the exchange constant in Fig. 1 show less than $1 \%$ variation with no trend with thickness, while the the odd mode assignment gives $20 \%$ variation with a steady trend with thickness. Similar results were obtained for all compositions. The significance of the deviation of the first few modes is discussed in Ref. 5 and in more detail by Bajorek. [6]

It was concluded, in agreement with Ref. 5 , that even number mode assignment should be used, and values of $A$ were obtained for a number of alloys in the composition range $60 \%$ to $100 \% \mathrm{Ni}$. The results given in Table I also include values of $A$ obtained by odd mode number assignment as well as experimental values of $M$ and $g$. The averaged data are plotted in Fig. 2, which also includes the data of Rusov for ease of comparison.

\section{DISCUSSION}

The lack of agreement between the work of Rusov and the present study is graphically shown in Fig. 2. It is certainly not due entirely to the difference in mode numbering. As shown in Table I, a change in numbering from even to odd simply does not give consistent values for $A$ independent of thickness. Furthermore, for the thickest films, the straight line fit is definitely poorer for odd numbering than for even numbering, although as seen in Fig. 1 the difference is not large. On the other hand, the work of Rusov appears to show the same internal consistency with the opposite mode numbering. He published a complete set of resonatice curves for one composition, so it is possible to make a similar comparison of the two

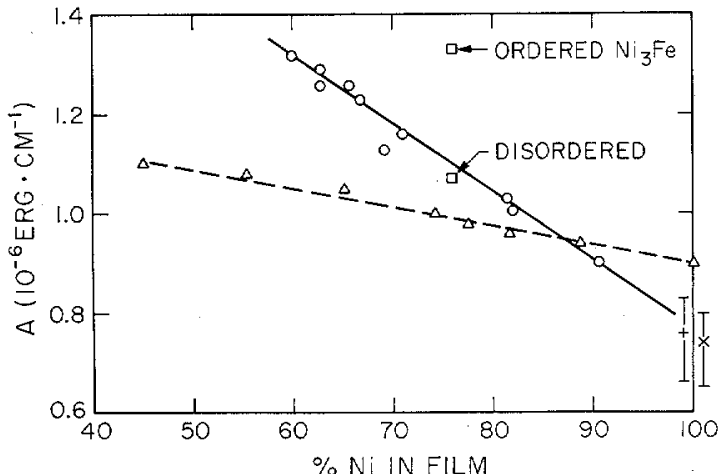

Fíg. 2. Exchange constant versus composition. Present study $O$; Johnson [8] $\square$; Rusov[4] $\Delta$; Nosé[1] +; and Janssen[7] $X$.

TABLE II

COMPARISON OF EXCHANGE VALUES FOR EVEN AND ODD MODE NUMBER ASSIGNMENT FOR $82 \% \mathrm{Ni}-18 \% \mathrm{Fe}$ FILMS

\begin{tabular}{|c|c|c||c|c|c|}
\hline \multicolumn{3}{|c||}{ Present Study } & \multicolumn{4}{|c|}{ Rusov (4) } \\
\hline \multirow{2}{*}{$\begin{array}{c}\text { Thickness } \\
\AA\end{array}$} & A $\left(10^{-6}\right.$ erg $\left.\cdot \mathrm{cm}^{-1}\right)$ & Thickness & \multicolumn{2}{|c|}{ A $\left(10^{-5} \mathrm{erg} \cdot \mathrm{cm}^{-1}\right)$} \\
\cline { 2 - 6 } & Eveń & Odd & $\AA$ & Even & odd \\
\hline 1040 & 1.01 & .60 & 1060 & 2.00 & .98 \\
1800 & 1.03 & .73 & 1500 & 1.31 & .92 \\
2000 & 1.01 & .76 & 2500 & 1.13 & .93 \\
2300 & 1.04 & .78 & 3300 & 1.06 & .97 \\
3900 & .97 & .83 & & & \\
6000 & 1.03 & .93 & & & \\
\hline Spread & $8 \%$ & $43 \%$ & $\%$ Spread & $62 \%$ & $6 \%$ \\
\hline
\end{tabular}

mode numbering schemes. Rusov's data given in Table II show excellent consistency in $A$ for odd mode designation and very poor consistency for even mode designation. The difference seems to be unreconcilable.

It may also be noted that for pure $\mathrm{Ni}$, values of $A$ published by Frait [2] are in good agreement with Rusov, while values given by Nosé and Janssen [7] are shown in Fig. 2 to be in good agreement with the extrapolation of the present study. A recent study by Johnson [8] of the ordered $\mathrm{Ni}_{3} \mathrm{Fe}$ system also shows results in agreement with the present study for the disordered alloy and a $25 \%$ increase for the ordered structure.

\section{REFERENCES}

[1] H. Nosé, J. Phys. Soc. Jap., 16, 2475 (1961).

[2] Z. Frait, Phys. Stat. Sol., 2, 1417 (1962).

[3] It is not feasible to list all published values. For films of approximately $80 \%$ Ni composition some representative publications in addition to Refs. 2, 4, and 5 follow.

Methfessel et al., Z. Ang. Phys., 14, 185 (1962).

P. Wolf, Z. Ang. Phys. 14, 212 (1962).

R. Weber and T. E. Tannenwald, Phys. Rev., 140, A498 (1965).

G. I. Lykken et al., J. Appl. Phys., 37, 3353 (1968).

M. Okochi, J. Phys. Soc. Japan, 28, 897 (1970).

[4] G. I. Rusov, Sov, Phys. Sol. State, 9, 146 (1967).

[5] C. H. Bajorek and C. H. Wilts, J. Appl. Phys. 42, 4324 (1971).

[6] C. H. Bajorek, Ph.D. Thesis, Calif. Inst. of Tech. (1971).

[7] M. M. P. Janssen, J. Appl. Phys. 41, 399 (1970).

[8] G. O. Johnson, Ph.D. Thesis, Calif. Inst. of Tech. (1972). 